\title{
Experiments in skill building for science communication
}

\author{
K. P. Madhu
}

University courses initiated three decades ago in India, with the intention of increasing the number of science communicators, have failed to produce the required manpower. So science communication in the country is still inadequate to meet the needs of media consumers. This article describes some experiments in capacity building for science communication and science reporting in India, and provides evidence that justifies seven strategic shifts to generate science communicators in the country.

Keywords: Optimization of resources, science communication, skill building, support systems, training strategies.

In 2017, the Journal of Science Communication ${ }^{1}$ came out with a special issue to examine the history of science communication in different countries. One cannot, of course, make comparisons between countries based on these papers because the authors focused on various aspects. While some papers dealt with the status of research on science communication in the country, others focused on political, social or educational aspects of science communication. However, it is quite apparent that there is indeed considerable variation in science communication between countries of the same region in the world as well as between countries with similar economic development. The special issue of the journal ${ }^{1}$, however, did not cover the Indian situation. This article focuses on measures to improve science communication in India.

Attempts to train science journalists in India were started in earnest by the National Council for Science and Technology Communication (NCSTC), New Delhi, in the mid 1980s. By the mid 1990s, there were about 12 institutions offering science communication. Some offered certificates, some others diplomas. There were universities that offered a Bachelor's degree and others, a Master's in Science and Technology Communication ${ }^{2}$. Two and a half decades later, the courses started closing down gradually. Rajput ${ }^{3}$ has rightly mourned the state of science communication in the country. After three decades, it is now evident that attempts to produce science communicators by offering Certificate, Diploma, Bachelor's or Master's degree courses have failed.

I was also a participant in this effort, as the Director of a course on science journalism in Jamia Millia Islamia, New Delhi in the late 1980s. The intake for the Postgraduate Diploma course was limited to those with a B Sc

K. P. Madhu lives at F-4/5 Mantri Avenue II, Panchavati, Pashan, Pune 411 008, India.

e-mail: kp.madhu2000@gmail.com degree. It has taken me nearly three decades to learn from that mistake: it was a wrong choice of target group. We should have trained those with a $\mathrm{Ph} \mathrm{D}$ degree instead.

Meanwhile, for years, I struggled to train media professionals, faculty and students to understand the nuances of science. But again, there were no appreciable results. In the last four years, I shifted the target group and started training scientists, science faculty, postdocs and researchers. There was an immediate impact ${ }^{4-7}$. I will argue that besides this shift in target group, there are other strategic shifts that are needed to successfully generate future science communicators in the country. To put the argument into an evidence based perspective, let me start with some background data.

\section{Media manpower and science}

In 2009, a questionnaire was sent out to the national broadcasters of 26 countries in the Asia-Pacific region to understand the human resource available for reporting science. This was done as part of a project funded by UNESCO and executed by the Asia-Pacific Institute for Broadcasting Development, an intergovernmental institution. The task was to create a resource for training broadcasters in the Asia-Pacific region to deal with science ${ }^{8}$. National broadcasters of 11 countries responded.

An analysis of the responses showed that, though most national broadcasters understood the need to report science, especially the science behind agriculture, environment, technology, medicine and health, there was no manpower adequately trained in the sciences and their applications. The outliers in this pattern were South Korea, which had a medical doctor with MD degree to head its medical and health-related programming, on the one hand, and on the other, Myanmar, which found inducting people with science background into broadcast media, an alien and strange concept. 
India is somewhere in the middle - scientific awareness is indeed disseminated by various agencies as well as the media. However, here again, manpower adequately trained to do justice to the complexities of science, technology and related subject areas is lacking. On TV, for instance, agriculture programming is still dominated by talking heads. And topics of current advances in science are never discussed even in $24 \mathrm{~h}$ news and current affairs channels. Newspapers that carry two pages of sports news everyday do not have even a half a page allocated to science. Though today's science transforms tomorrow's society...

Evidently, this is because of the lacunae in the system that is expected to provide the manpower for the task. In tertiary education, there is no intrinsic connection between the Departments of Science and the Departments of Arts, where media belongs. This disjunction between science and the media is perhaps the reason why science communication has not flourished in India.

\section{Science communication courses}

In 2016, I did a rapid assessment survey of the different types of journalism and mass communication courses offered by various types of educational institutions to understand the factors behind the failure of the educational system to produce an adequate number of science communicators in the country ${ }^{9}$. The survey covered Central Government, State Government and private sector institutions and aimed to understand the broad patterns of mass media/journalism courses in general, and science and technology communication courses in particular. Discussions with students, alumni, faculty and course directors confirmed that journalism/mass communication courses are not equipped to provide the knowledge, skills and attitudes required for science communication.

The closure of some of the science communication courses was attributed to the following:

1. Students admitted to the courses had 12 or 15 years of prior formal education. A B Sc degree does not prepare students to read scientific papers critically or to even comprehend them.

2. The core teaching staff came from other disciplines: engineering, management, etc. A large number of guest lecturers without any linkages between topics and inadequate exposure to professionals working in the field were the other reasons as well.

3. The textbooks did not reflect Indian media realities. They were mostly written by people outside the country.

4. The earlier batches of science journalism/communication students had difficulty in competing with regular media students when they entered the employment market.
5. A few years ago, NCSTC started withdrawing financial support for these courses. It is clear that the experiments in initiating courses in science journalism did not have the envisioned impact - though there are, indeed, cases of rare science communicators who have emerged from such courses.

It is in the context of this background that I present the experiments in capacity building to test a series of hypotheses and identify the strategic actions needed to improve the coverage of science in Indian media.

\section{Strategy 1: Train people with a science background}

Content is king is the axiom for the media industry. The media wants people who can handle content. This point was raised by N. Ram, the then Editor of The Hindu, a leading Indian newspaper, in a UNESCO meeting held early this century to discuss the model curriculum for journalism. Of course, the academicians could not deliver the curriculum that the industry demanded because the focus remained on building journalistic skills rather than the skills needed to take control over scientific content $^{10,11}$.

The opportunity to test this came initially as onemonth-long workshops on science video production, for students of IISERs and IITs, organized in IISER Pune during December vacations. Four such workshops held from 2011 to 2015, demonstrated that science students can easily be trained to make science videos ${ }^{12}$. However, the scientific content in the videos was poor. Science students - even those in IISERs and IITs - do not have fully developed scientific rigour to deal with contemporary scientific content.

Training people with scientific content - scientists, or even $\mathrm{PhD}$ scholars - in a regular university course is impossible. An ideal course for this target group has to be intensive and short, unlike the usual educational endeavours which are extensive and of long duration. So, different types of workshops were designed to test the concept.

First, in 2014, a two-week workshop targeting those with a minimum of a Master's degree in science was designed. With support from Vigyan Prasar, New Delhi, the workshop was conducted in IISER Pune in 2014 and 2015. Initially, the workshop was open to those with a Master's in journalism or mass media, with a hope of creating a network between media and science professionals. Though this hope did not materialize, it was abundantly clear that the long-term impact of training is higher among students persuing their $\mathrm{Ph} \mathrm{Ds}$ in science those who had just finished their Master's degree. So, for similar workshops held in 2016 and 2017, the target group was shifted to those doing their $\mathrm{Ph} \mathrm{D}$ or those who had completed a $\mathrm{Ph} \mathrm{D}$. These trained professionals started contributing to Current Science and 
later to Vigyan Prasar's India Science News Wire, besides other outlets such as India BioScience and Science Reporter.

Next, from 2016, a series of five-and-half-days workshops was conducted under the aegis of Current Science $^{13}$. Though the entry point was initially pegged at a Master's in science, to allow for identification of potential Ramaseshan Fellows, the uptake was primarily those who had a $\mathrm{Ph} \mathrm{D}$ degree. Scientists, Associate/Assistant Professors and postdocs were the major participants. These workshops led to four pages of credible and engaging news about Indian science in Current Science under 'Science Last Fortnight'.

Though workshops of shorter duration were conducted in collaboration with the Venture Centre, Pune, it was found that reducing the duration of the workshop would be suboptimal. The number of participants in all the workshops above was kept at 14 or below, according to international practices in the media. In 2017, the same one-week workshop was conducted for 30 participants in Guru Jambheshwar University of Science and Technology, Hisar. However, this did not yield the same results, showing, once again, that the number of participants is also a critical factor in training ${ }^{14}$.

\section{Strategy 2: Leverage on on-line interaction}

If content is king, then style is queen. $\mathrm{Ph} \mathrm{D}$ scholars, scientists and faculty members may have better control on the content than the journalists. But they do not have the style. Any scientific work, even the most important ones, when presented badly, does not make an impression; whereas, even minor advances make an impact when presented with style. And style, of course, does not evolve even in a one-month workshop.

A part of the style is influenced by the writer's awareness about the relationship between science and society. Most scientists are not aware of the sociology of science, the economics of science, the politics of science, the philosophy of science and in some cases, even the methodological underpinnings of science, because these topics are not covered in science syllabi. This lacuna in education had to be filled, at least partially, to make the experiment successful.

Thus the one- and two-week workshops were preceded by on-line interactions to orient participants to issues related to science and the Fundamental Duties of citizens under the Constitution of India ${ }^{15}$, the vision ${ }^{16}$, policies ${ }^{17}$, plans and programmes of the Government, scientific infrastructure in the country ${ }^{18}$, its performance compared to other countries ${ }^{19}$, etc.

After the workshop, on-line interactions continued, but focused more on providing feedback and mentoring. Continued practice of a skill under critical feedback and advice was the major input for improving the quality and to develop individual style.
Style does not develop during the workshop, but over time. So Google Docs, a collaborative platform for writing and group editing, was used to provide a ground for continued practice. On-line interaction is more than adequate for transmission of knowledge, as organizations like the Khan Academy and later other massive open on-line courses (MOOCs), have demonstrated to the world. However, unlike in education, in training, there is a focus on improving skills and attitudes besides imparting knowledge. Therefore, on-line and face-to-face interactions had to be combined to complement each other's strengths, to fulfil all three functions of training.

Today, the internet is a given - unlike the times when DST-NCSTC designed various science communication courses in universities. We need to strategically use it for training science communicators. However, on-line courses alone do not allow the intense individual social interaction that is necessary for shifting attitudes and beliefs - a limitation that can be overcome by the face-toface workshops. The combination of extensive on-line interactions and intensive interactions in the workshops is a mix that has proved to be cost-effective in generating future science communicators in a time-bound manner; but not for sustaining their output. A combination of the next three strategies will address this issue.

\section{Strategy 3: Leverage on the needs of the target group}

To each, as per needs. The needs of those pursuing science academically differ from those who are dealing with science in the media. Academics need to write papers that are acceptable in high impact factor journals and this is a major motivating factor in applying for such workshops. The ability to reach across to the public is seen only as a secondary, but desirable, outcome.

The primary need of the participants has to be met so that the purpose of science communication to the public is also served. The contents and processes of the workshop, therefore, have to be designed for this. Subjugating the primary intention of the workshops to the primary needs of the participants is a necessary part of the strategy - one that is win-win for all. And feasible, especially since both require one skill in common: the ability to write well.

It is not difficult to align the needs of the nation to those of individuals. Thus, for example, a video production workshop may target scientists who want to publish in say, Journal of Visualised Experiments or a video article in Dialogue, or a video abstract for the New Journal of Physics. After a two-week hands-on training, participants can easily make science news also. It is the same technology, same techniques, same tools and same tricks. Only the target groups and, therefore, the pitch in the content of communication, are different. 
If, after witnessing Space Applications Centre and NISCAIR fail at attempts to create a Science TV channel, DST wants to succeed, it would be advisable to generate adequately skilled manpower to handle visual media among scientists, researchers and science faculty rather than trying to leverage on existing manpower and video content.

It is true that many scientists may not use the skills so gained, for popular communication. However, the results so far show that even the meagre output is far more than can be expected from the few thousand alumni of Certificate, Diploma, Bachelor's and Master's degree courses on science communication over three decades. Box 1 gives the number of workshops and people trained in four years and Box 2 provides the outcome in the last two years.

As the workshops organized by Current Science demonstrate, participants are willing to pay for gaining communication skills. The costs incurred for training, therefore, are minimal. To convert the present trickle to a torrent, within the next three years, three more strategies are recommended.

\section{Strategy 4: Create platforms for output}

Fragmentation of audience has created new media niches. The media scenario has changed drastically in recent decades. Viewers, listeners and readers are fragmented due to the emergence of a large number of media channels. Also, with the advent of the internet, media consumption habits have changed. A new set of media professionals, now called citizen journalists, has evolved from the educated class, to fill the new media niches.

After an initial phase of resistance, traditional media started co-opting citizen journalists. The falling subscription revenue on the one hand, and reduction in advertising revenue due to audience fragmentation on the other, made content production at the scale needed financially difficult. Accepting citizen journalists made business sense. If engaging scientific content is available, especially at no cost, the media will gladly carry the output from the trained Ph Ds.

Thus, in February 2016, a weekly column of 600 words that reported news about science done in Pune was started in Sakaal Times, which later expanded to cover science in Maharashtra. Within a few weeks, the team became capable of increasing the scope to cover national scientific

\begin{tabular}{|lc|}
\hline \multicolumn{2}{|c|}{ Box 1. Workshop details } \\
\hline Number of workshops (October 2014-December 2017) & 11 \\
Total number of participants in the workshops & 150 \\
Number of participants who wrote for non-specialists & 50 \\
after the workshops & \\
\hline
\end{tabular}

advances. Thus it grew and transformed into a 1700-word column in Current Science ${ }^{20}$, and from 2017, it expanded to a 3400-word column. To manage the spillover due to lack of space in Current Science, a website had to be developed $^{21}$. Developing a platform for delivering usable scientific content to the Indian media would be the next logical step.

Even though the news reports are written by $\mathrm{Ph} \mathrm{Ds}$, there can be errors in the representation of the thrust of research being reported. Misrepresentations by journalists have already caused considerable consternation among scientists and led to researchers avoiding journalists. Therefore, the news reports are sent to the scientists whose work is being reported for validation. Over time, scientists have now started sending their papers before publication date so that those also can be reported as news. This trust-building exercise has to be a part of science reporting and communication.

\section{Strategy 5: Create market linkages}

An activity becomes sustainable when benefits overcome costs. When the people who are trained are brought together for generating news items related to advances made in the science behind agriculture, medicine, technology, environment, energy, etc. they take on the nature of a self-help group. Typically, when a self-help group is formed, there is a need to facilitate market linkages. The word 'market linkage' has an economic facet.

In the case that we presented, there was no financial benefit to the members of the self-help group. However, they profited in terms of improving their social and academic stature and kept improving their style to improve their 'marketability'. This was benefit enough from the costs incurred in terms of time and effort.

Nevertheless, this is not a sustainable model. The dropout rate among those who are trained is high. Scientists and faculty members will want to use the newly developed skills for writing papers and reviews for their peers - for scientific communication, not for science communication for the benefit of the public. The pressure of 'publish or perish' is too high. Though there will be a few who will continue and derive pleasure from writing for non-specialists, in the final analysis, science communication would remain a secondary activity. Thus, though the earlier strategies may be good enough to produce

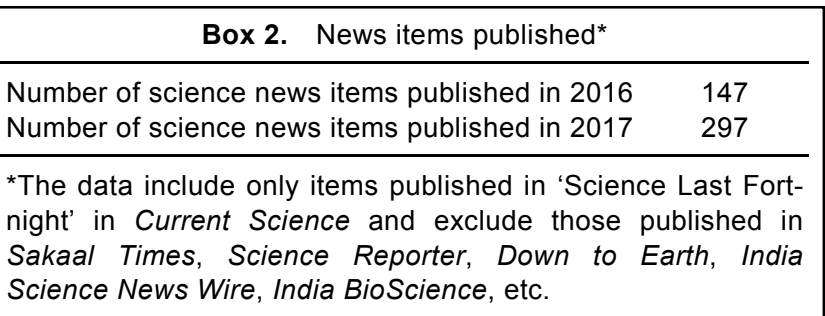


future Balasubramanians and Narlikars, it is inadequate to meet the needs of the country.

To make $\mathrm{Ph} \mathrm{Ds}$ in science plunge into media, to lead them to the path that Killugudi S. Jayaraman and R. Ramachandran took in PTI in the 1980 s, we may need to create adequate market linkages, support structures that do not exist as yet. Such linkages are not difficult to create, given the present state of the media market in India. Vigyan Prasar has already moved in that direction by initiating India Science Wire ${ }^{22}$.

\section{Strategy 6: Train journalism students in science communication}

Give Caesar his due. All the strategies listed above do not preclude the need to train future media professionals on the intricacies of science reporting. Most media students, that I have trained, have an aversion to science and mathematics - one of the reasons for their choice of media or journalism as a subject in tertiary education. Some even have anti-science attitudes. This does not bode well for the future of science communication in the country.

Many of the students of media today will be media gatekeepers tomorrow. So there is an urgent need to sensitise this target group about the need for science communication, to reduce their dislike for science as a subject and to generate a healthy curiosity about science as a part of the socio-cultural activity in Indian cities.

To test this, I conducted science communication courses for students of Master's in journalism and mass communication and of Master's in visual media. The experiments, repeated twice for journalism students and twice for visual media students, in Amrita School of Arts and Sciences, Kochi, confirmed that the workshops can indeed build capacity to enable media students to report science ${ }^{23}$, but greater efforts are needed from their side to complete the tasks. For the students, the cost of effort is more than the benefits. Like in the postgraduate Diploma course in Jamia Millia Islamia in the 1980s, none became productive in the area of science communication in their professional life. However, due to the workshops, all participants have pro-science attitudes. Thus, such courses are useful to create an enabling environment in the mainstream media for science communication in the country.

Though the students from journalism and mass media may not be able to report advances in science and technology due to their difficulties in comprehending scientific papers and patents, they may be able cover conferences, meetings, policy announcements and budget allocations for science. These are areas into which very few $\mathrm{Ph} \mathrm{Ds}$ in science trained so far have ventured. Moreover, they can also be oriented easily to report on scams and scientific misconduct, as the watchdogs of any misconduct in society.

In the course of two such workshops for journalism students, I noticed a tendency for the journalism students to prefer English language media. This means that the quality of regional language newspapers and magazines will go down further in the next decade.

\section{Strategy 7: Train scientists to write science in regional languages}

Talk to people in their language. Though I confess that this last strategy is not tested adequately, this advice given by Buddha to his disciples should work even in the modern context.

If the State Science and Technology Councils and regional science-oriented NGOs decide to test it, I would recommend the use of all earlier six strategies to improve science reporting in regional language media within a reasonable time-frame.

Though I have noticed attempts to improve communication of science in Kannada, Marathi and Malayalam by organizations and individuals, unless the State Governments facilitate and synergize these efforts, the general populace will not be able to appreciate science or to find it necessary to support more funding for research. Though the language-state connection has become diffuse in the recent decades, evolution of Indian languages to deal with the rapidly evolving scientific thought depends on the intervention of the States.

\section{Conclusion}

The experiments described under the first six strategies show that short-term workshops can indeed generate the manpower required for reporting science and related topics, if the participants targeted have adequate background in scientific research.

To develop skills for print media reporting, a minimum duration of one week is needed if the participants have a $\mathrm{Ph} \mathrm{D}$. If they have only a Master's degree, two weeks are needed; yet it did not have the same impact in terms of the outcome: the output of rigorous, yet engaging scientific content.

For capacity building to report science using videos, a minimum duration of two weeks is needed if the participants have a $\mathrm{Ph} \mathrm{D}$, whereas for those with a Master's degree, one month is needed. However, whether the training would be translated into public-oriented content is yet to be tested, along with creation of platforms for dissemination.

The outcome of these short-term intensive courses targeting $\mathrm{Ph} \mathrm{D}$ scholars and postdocs along with extensive engagement of those who are trained, is better than the two-year courses offered as a Master's in science and technology communication. What we failed to achieve in three decades could be achieved in three years.

Instead of creating new courses in the tertiary educational system, NCSTC could fund two-week courses 
targeting science faculty in the Human Resource Development Centres of UGC, previously known as Academic Staff Colleges. The rule of UGC, to keep the minimum number of participants in such workshops to 30 , comes into conflict with the concept of a maximum of 14 , adopted by all highly productive workshops. However, there is yet another UGC rule that gives extra weightage for participation in two-week workshops. Of course, it remains to be tested whether two-week workshops for 30 participants would be as effective as a one-week workshop for 14 participants. One should suspect that Stephen Leacock's ${ }^{24}$ doubt, about the applicability of simple arithmetic where people are involved, might be valid. Another set of experiments may need to be undertaken to test this possibility.

There is also a need to bring out an Indian textbook for science communication, to be taught as a journalism/mass media course and train media faculty to use it. An open, on-line course can supplement the needs of this target group.

Besides science communicators, specialists in agriculture communication, health communication, disaster and earth science communication, technology communication and environment communication, etc., will also evolve naturally if the relevant ministries and departments act in a parallel manner, using the strategies listed above.

Vigyan Prasar, as an autonomous organization, can leverage on the output of those who are thus trained. This will be useful to network content creators, especially at this time when efforts to set up a science channel have been taken up for the third time in India.

While this will improve the coverage of science in the Indian media, it will also improve the quality of papers and reviews being published by Indian researchers. Ultimately this too is important from a national perspective. In terms of numbers, research publications by Indians are doubling every decade. Along with this commendable rise in quantity, there is a need to improve quality too, as all journal editors will agree. Refresher courses in this area, as organized by the science academies in India for physics and other subjects and trending topics, can help improve the quality of Indian scientific journals.

1. JCOM - J. Sci. Commun. (Spec. Issue), 2017, 16(3).

2. Rajput, Abhay, S. D., Science communication: careers and courses in India. Curr. Sci., 2008, 95(11), 1513.

3. Rajput, Abhay, S. D., Science communication as an academic discipline: an Indian perspective. Curr. Sci., 2017, 113(12), 2262 2267.
4. Iqbal, Sarah, Factories, microbes and biotechnology. Curr. Sci., 2016, 111(3), 459-460.

5. Tekam, Manish K., Joker of the climate system: aerosols control climate. Curr. Sci., 2016, 111(5), 785-786.

6. Iqbal, Sarah, Cool ways to deliver curcumin: practical neutraceutical. Curr. Sci., 2016, 110(9), 1608-1609.

7. Khullar Bhavya and Iqbal, Sarah, Size matters: nanoparticles in cancer therapy. Curr. Sci., 2016, 111(10), 1583-1584

8. Madhu, K. P. and Jain, Savyasaachi, Broadcasting Science, UNESCO, 2010; https://unesdoc.unesco.org/ark:/48223/pf0000$\underline{192165}$

9. https://scienceandmediaworkshops.files.wordpress.com/2015/11/j ournalism-and-communication-coursesreview.pdf

10. Model Curricula for Journalism Education: a compendium of new syllabi, UNESCO, 2013; http://unesdoc.unesco.org/images/0022/ 002211/221199E.pdf

11. Developing a Science Journalism Course for Developing Countries, UNESCO, 2007; https://www.upf.edu/pcstacademy/ docs/ 200706 unesco.pdf

12. These videos are available at https://www.youtube.com/channel/ UCFOS11zGpF0Sn9WbgP22uXQ

13. Brief reports of the workshops are available at https://www. currentscience.ac.in/Volumes/111/02/0247.pdf; https://www.currentscience.ac.in/Volumes/111/09/1564.pdf; https://www.currentscience.ac.in/Volumes/112/09/1802.pdf; https://www.currentscience. ac.in/Volumes/113/06/1020.pdf

14. https://scienceandmediaworkshops.files.wordpress.com/2017/11/ class-strength_structure-function.pdf

15. Article $51 \mathrm{~A} \mathrm{~h}$ in Part IV A Fundamental Duties available at http://lawmin.nic.in/olwing/coi/coi-english/Const.Pock\%202Pg.Rom8Fsss(8).pdf

16. India as a Global Leader in Science, Science Advisory Committee to the Prime Minister, DST, New Delhi, 2010; http://euindiacoop.org/el/document11102010407.265806e-05.pdf (accessed in March 2017).

17. Science Technology and Innovation Policy 2013; http:// www.dst.gov.in/sites/default/files/STI\%20Policy\%202013-English. pdf (accessed in March 2017).

18. Directory of Research and Development Institutions, DST, New Delhi, 2015; http://www.nstmis-dst.org/PDF/directory-of-r-and-dinstitutions-2015.pdf

19. UNESCO Science Report Towards 2030; http://unesdoc.unesco. org/images/0023/002354/235407e.pdf

20. The first issue of 'Science Last Fortnight' in Current Science can be accessed from: https://www.currentscience.ac.in/Volumes/110/ 06/0962.pdf

21. STEAMindiaReports; https://steamindiareports.com

22. India Science Wire; http://vigyanprasar.gov.in/isw/isw.htm

23. Science News bulletin in Malayalam, made by visual media students at Amrita School of Arts and Sciences, Kochi; https://www. youtube.com/watch? $\mathrm{v}=\mathrm{n}=\mathrm{EPGWKqftM} \& \mathrm{t}=32 \mathrm{~s}$

24. Stephen, L., A, B and C: The human element in Mathematics, http://www.online-literature.com/stephen-leacock/literary-lapses/40/

Received 3 October 2018; accepted 1 December 2018

doi: $10.18520 / \mathrm{cs} / \mathrm{v} 116 / \mathrm{i} 3 / 366-371$ 